\title{
Lumbar Spinal Stenosis Severity by CT or MRI Does Not Predict Response to Epidural Corticosteroid versus Lidocaine Injections
}

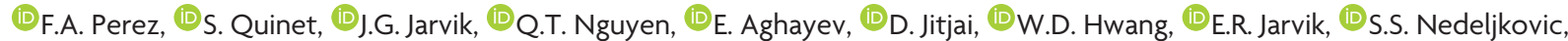

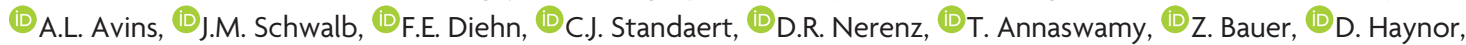

(1).J.. Heagerty, and $\oplus^{\oplus}$ J.L. Friedly

配

\begin{abstract}
BACKGROUND AND PURPOSE: Epidural steroid injections may offer little-to-no short-term benefit in the overall population of patients with symptomatic spinal stenosis compared with lidocaine alone. We investigated whether imaging could identify subgroups of patients who might benefit most.

MATERIALS AND METHODS: A secondary analysis of the Lumbar Epidural Steroid Injections for Spinal Stenosis prospective, double-blind trial was performed, and patients were randomized to receive an epidural injection of lidocaine with or without corticosteroids. Patients ( $n=350$ ) were evaluated for qualitative and quantitative MR imaging or CT measures of lumbar spinal stenosis. The primary clinical end points were the Roland-Morris Disability Questionnaire and the leg pain numeric rating scale at 3 weeks following injection. ANCOVA was used to assess the significance of interaction terms between imaging measures of spinal stenosis and injectate type on clinical improvement.

RESULTS: There was no difference in the improvement of disability or leg pain scores at 3 weeks between patients injected with epidural lidocaine alone compared with corticosteroid and lidocaine when accounting for the primary imaging measures of qualitative spinal stenosis assessment (interaction coefficients for disability score, $-0.1 ; 95 \% \mathrm{Cl},-1.3$ to 1.2; $P=.90$; and for the leg pain score, 0.1 ; $95 \% \mathrm{Cl}$, -0.6 to $0.8 ; P=.81$ ) or the quantitative minimum thecal sac cross-sectional area (interaction coefficients for disability score, $0.01 ; 95 \% \mathrm{Cl}$, -0.01 to $0.03 ; P=.40$; and for the leg pain score, $0.01 ; 95 \% \mathrm{Cl},-0.01$ to $0.03 ; P=.33$ ).
\end{abstract}

CONCLUSIONS: Imaging measures of spinal stenosis are not associated with differential clinical responses following epidural corticosteroid injection.

ABBREVIATIONS: $\mathrm{AP}=$ anteroposterior; $\mathrm{ESI}=$ epidural steroid injection; $\mathrm{ML}=$ mediolateral; $\mathrm{NRS}=$ numeric rating scale; $\mathrm{RDQ}=$ Roland-Morris Disability Questionnaire

umbar spinal stenosis is a common cause of low back pain, -radicular pain, and neurogenic claudication leading to disability. ${ }^{1,2}$ Imaging for lumbar stenosis is controversial because there is

Received January 24, 2019; accepted after revision March 19.

From the Department of Radiology (F.A.P., J.G.J., Q.T.N., D.H.), Comparative Effectiveness, Cost and Outcomes Research Center (J.G.J., P.J.H., J.L.F.), Departments of Neurological Surgery (J.G.J.), Health Services (J.G.J.), Orthopedics and Sports Medicine (Q.T.N.), Biostatistics (P.J.H.), and Rehabilitation Medicine (J.L.F.), University of Washington, Seattle, Washington; Department of Radiology (S.Q.), College of Wisconsin, Milwaukee, Wisconsin; Spinal Centre Division (E.A.), Schulthess Klinik, Zurich, Switzerland; Oregon Health Sciences University (D.J.) Portland, Oregon; TRA Medical Imaging (W.D.H.), Tacoma, Washington; University of Washington Medicine (E.R.J.), Seattle, Washington; Department of Anesthesiology, Perioperative and Pain Medicine and Spine Unit (S.S.N.), Harvard Vanguard Medical Associates, Brigham and Women's Hospital, Boston, Massachusetts; Division of Research (A.L.A.), Kaiser Permanente Northern California, Oakland, California; Department of Neurosurgery (I.M.S., D.R.N.), Henry Ford Medical Group, Detroit, Michigan; Department of Radiology (F.E.D.), Mayo Clinic, Rochester, Minnesota; Department of Physical Medicine and Rehabilitation (C.J.S.), University of Pittsburgh School of Medicine, Pittsburgh, Pennsylvania; Department of Physical Medicine and Rehabilitation (T.A.), VA North Texas Healthcare System, Dallas, Texas; and Cancer and no consistent correlation between the severity of stenosis by imaging and the severity of symptoms. ${ }^{3-5}$

Spinal stenosis symptoms may, in part, be due to nerve root inflammation and/or ischemia related to compression. ${ }^{6}$ Epidural steroid injections (ESIs) are often used to reduce local inflamma-

Blood Disorders Center (Z.B.), Seattle Children's Research Institute, Seattle, Washington.

This work was supported by the Agency for Healthcare Research and Quality (grants 1R01HS019222-01 and 1R01HS022972-01) and the Patient-Centered Outcomes Research Institute (contract CE-12-11-4469).

Paper previously presented at: American Society of Neuroradiology Annual Meeting and the Foundation of the ASNR Symposium, April 25-30, 2015; Chicago, Illinois. "Qualitative Assessment of Lumbar Spinal Stenosis by CT and MRI: Stenosis Severity Does Not Predict Response to Epidural Glucocorticoid Injections."

Please address correspondence to Janna L. Friedly, MD, Department of Rehabilitation Medicine, Comparative Effectiveness, Cost and Outcomes Research Center, University of Washington, Box 359859, Seattle, Washington 98104; e-mail: friedlyj@uw.edu

- Indicates open access to non-subscribers at www.ajnr.org

= Indicates article with supplemental on-line tables.

http://dx.doi.org/10.3174/ajnr.A6050 
tion and therefore improve lumbar spinal stenosis symptoms. ${ }^{7-9}$ Given the variable results with ESI, there is a need to understand the patient, disease, and procedural factors associated with improved outcomes. Patients with severe nerve root compression due to disc herniation may be less likely to benefit from an ESI, perhaps related to the predominance of mechanical compression rather than inflammation. ${ }^{10}$ However, there is a lack of rigorous data to determine whether imaging severity predicts the response to ESI in lumbar central spinal stenosis. ${ }^{10-15}$ Prior studies examining the relationship between outcomes of ESI for spinal stenosis and imaging severity have been small and uncontrolled, leading to mixed results.

The Lumbar Epidural Steroid Injections for Spinal Stenosis (LESS) multicenter, double-blind randomized trial found that ESIs offered little-to-no short-term benefit compared with an epidural injection of lidocaine alone. ${ }^{16}$ However, the primary analysis of this study did not specifically assess whether imaging spinal stenosis severity predicted a differential response to injections of epidural corticosteroid and lidocaine versus lidocaine alone. $^{17}$

Our objective was to determine whether lumbar spine MR imaging or CT measures of lumbar spinal stenosis severity predicted a response to epidural injection of corticosteroid and lidocaine versus lidocaine alone. We hypothesized that patients with less severe central stenosis, in which inflammation may play a larger role than mechanical compression, would have a more favorable response to corticosteroid injections compared with treatment with lidocaine alone.

\section{MATERIALS AND METHODS \\ Patients}

A secondary, retrospective analysis of patient data from the LESS trial was performed (ClinicalTrials.gov identifier: NCT01238536). ${ }^{16,18}$ The study was Health Insurance Portability and Accountability Act-compliant, we obtained institutional review board approval at each of the 16 clinical sites in the United States, and patients provided written informed consent. Detailed inclusion and exclusion criteria and patient characteristics have been previously described. ${ }^{16}$ Inclusion criteria were patients 50 years of age and older with MR imaging or CT evidence of lumbar central spinal stenosis assessed by an enrolling clinician; moderate-to-severe symptoms consistent with neurogenic claudication with an average pain numeric rating scale (NRS) of $\geq 5$ (on a scale of $0-10$ with 0 indicating no pain and 10 indicating most severe pain) for pain in the lower back, buttock, leg, or a combination of these sites on standing, walking, or spinal extension in the past week; and a score of $\geq 7$ on the Roland-Morris Disability Questionnaire (RDQ), in which scores range from $0-24$, with higher scores indicating greater disability. Patients with a history of prior lumbar surgery, ESI in the previous 6 months, or spondylolisthesis requiring surgery were excluded.

\section{Interventions}

Patients were randomized to receive an epidural injection of either corticosteroid with lidocaine $(n=200)$ or lidocaine alone $(n=200)$. Injections were performed by 26 board-certified anesthesiologists, physiatrists, and radiologists with ESI expertise and trained to perform the injections using standardized techniques. Study physicians and outcome assessors were blinded to the injectate administered. Physicians chose either an interlaminar or transforaminal injection approach based on clinical judgment and experience because there remains uncertainty about the relative effectiveness. Interlaminar injections were performed 1 spinal level below the maximal canal stenosis as determined by the treating physician or, if not technically feasible, as close to the level of maximal stenosis as possible. Interlaminar injections were not performed at the level of maximum stenosis to avoid the theoretic possibility of worsening thecal sac compression by the epidural injectate, and a prior study has demonstrated consistently $>1$ spinal level of epidural injectate dispersal following interlaminar injection. ${ }^{19}$ Transforaminal injections were performed at the most symptomatic nerve root level and, in many cases, with multilevel and/or bilateral injections to optimize injectate delivery. ${ }^{20}$ Under fluoroscopic guidance, an 18- to 25-ga Quincke or Tuohy spinal needle was used to inject $2 \mathrm{~mL}$ of $0.25 \%-1 \%$ lidocaine followed by $1-3 \mathrm{~mL}$ of corticosteroid or $1-3 \mathrm{~mL}$ of $0.25 \%-1 \%$ lidocaine. The volume, dose, and type of corticosteroid were determined by the treating physician (60-120 mg of methylprednisolone; 6-12 mg of betamethasone; 60-120 mg of triamcinolone; or 8-10 $\mathrm{mg}$ of dexamethasone). Additional injection procedure details are available. ${ }^{16,18}$

\section{Clinical Outcomes}

Detailed outcome measures for this trial have been previously described. ${ }^{16}$ For the current analysis, the 2 predetermined primary outcomes were the RDQ and mean leg pain NRS at 3 weeks following injection because the greatest clinical response to the injection was observed at that time point in the LESS trial. Secondary clinical outcome measures included the following: RDQ and leg pain NRS at 6 weeks postinjection; back pain NRS and mean of leg and back pain NRS at 3 and 6 weeks postinjection; and the Swiss Spinal Stenosis Questionnaire ${ }^{21}$ symptom subscale (scores of 1-5, with higher scores indicating worse symptoms) and the physical function subscale (scores of 1-4, with higher scores indicating worse function) at 3 and 6 weeks postinjection.

\section{Imaging}

MR imaging studies included at least sagittal T1, sagittal T2, and axial T2-weighted images; CT studies included at least axial softtissue algorithm images. Analysis was limited to patients with lumbar spine CT or MR imaging studies performed within 2 years of study enrollment (350/400 enrolled patients). Imaging studies were anonymized and reviewed on a PACS at the data-coordinating center for qualitative and quantitative measures of lumbar central stenosis.

\section{Qualitative Imaging Measures of Lumbar Central Stenosis}

Qualitative central stenosis was determined for all eligible patients at each lumbar spine level on CT (41 studies) or MR imaging (309 studies) on the basis of the degree of central canal narrowing on axial images relative to its expected normal cross-sectional area as follows: $0=$ normal, $1=$ mild stenosis, less than or equal to one-third loss of the expected normal area; $2=$ moderate stenosis, 
one-third to two-thirds loss of the expected normal area; $3=$ severe stenosis, more than two-thirds loss of the expected normal area. $^{22,23}$ For 308 of 309 patients with MR imaging studies, we qualitatively assessed lumbar spine perineural CSF effacement at each lumbar spine level as a secondary measure on axial T2 MR imaging using the grading system of Lee et $\mathrm{al}^{24}: 0=$ normal, $1=$ mild, 2 = moderate, and $3=$ severe $(1 \mathrm{MR}$ imaging study could not be assessed on this measure due to missing axial T2 sequences). For each patient, we assessed up to 5 lumbar spine levels qualitatively and derived several single-summary measures of overall spinal stenosis. The predetermined primary qualitative imaging measure was the maximum qualitative central stenosis grade representing the worst level of stenosis. Other secondary measures included the maximum qualitative CSF effacement score and the mean central stenosis and qualitative CSF effacement scores to represent the overall degree of stenosis, taking into account the degree of stenosis at multiple levels.

Two experienced imaging readers (W.D.H., a fellowshiptrained neuroradiologist with 5 years of experience; and Q.T.N., a radiology physician assistant with 17 years of experience interpreting spinal imaging) performed qualitative imaging assessment blinded to patient injectate and symptoms. Imaging studies were randomly divided between the 2 readers for review. Seventyone studies were reviewed by both readers independently to assess interrater reliability.

\section{Quantitative Imaging Measures of Lumbar Central Stenosis}

We excluded patients with CT studies from quantitative analysis because we could not reliably determine these measurements on CT. We performed quantitative analysis at each lumbar spinal level for 304 of 309 patients who underwent MR imaging; due to file-format limitations, cross-referencing of axial and sagittal images could not be performed for 5 patients.

The cross-sectional thecal sac area was measured at each intervertebral level by tracing its outline with an ROI tool on axial T2 images. Because axial images were not always acquired parallel to the intervertebral disc level and perpendicular to the spinal canal, a correction factor was applied to each level by multiplying the measured cross-sectional area by the cosine of the angle between the axial images and a line parallel to the adjacent vertebral body endplate. We measured the maximum anteroposterior (AP) and mediolateral (ML) diameters of the thecal sac on axial T2 images, and the AP thecal sac diameter was also determined for each lumbar intervertebral disc level using midline sagittal T2 images.

For each patient, readers quantitatively assessed up to 5 lumbar spine levels, and several single-summary measures of overall spinal stenosis were derived. The predetermined primary quantitative imaging measure was the minimum, angle-corrected, thecal sac cross-sectional area representing the worst level of stenosis. Other secondary measures included the mean of the angle-corrected, thecal sac cross-sectional area (as a summary measure for multilevel stenosis) as well as minimum and mean summary measures for each remaining measure (Table); non-angle-corrected measures were also evaluated.

Five trained readers performed quantitative assessment
(F.A.P. and S.Q., fellowship-trained neuroradiologists both with 5 years of experience; E.A., an orthopedic surgeon; D.J. and E.R.J., undergraduate research assistants) blinded to patient injectate and symptoms. After training, the readers reviewed a verification set of $20 \mathrm{MR}$ imaging studies or 100 lumbar spinal levels to evaluate reliability before beginning study imaging review.

All imaging studies were then divided among the 5 trained readers for review. Statistical analysis was performed using data from a single reader per patient.

\section{Statistical Analysis}

Data analysis was performed using $\mathrm{R}$ statistical and computing software, Version 3.1.2 (http://www.r-project.org/). ${ }^{23}$

We evaluated the interrater agreement of qualitative assessments of stenosis severity between the 2 experienced readers using unweighted $\kappa$ analysis. For the quantitative imaging predictors, interrater reliability was assessed among the 5 trained readers using an intraclass correlation coefficient analysis of the verification imaging studies.

ANCOVA for each potential imaging predictor and each clinical outcome was constructed with adjustments for the baseline clinical measure value and patient recruitment site. The dependent variable in each model was the clinical outcome measure. Independent variables were injectate group (lidocaine alone versus corticosteroid and lidocaine) and the imaging measure of spinal stenosis severity. The primary statistical analysis was whether the effect of injectate type on a clinical outcome differed depending on an imaging measure of stenosis severity. This was assessed by including an imaging measure by injectate type interaction term in the model and evaluating the statistical significance with a likelihood ratio test. For post hoc comparison testing, the Tukey Honestly Significant Difference test was performed. For the predefined analysis using primary imaging measures and primary clinical end points, statistical significance was $P<.05$. For exploratory analysis of secondary measures, a predetermined statistical significance threshold of $P<.01$ was used to minimize false discoveries.

\section{RESULTS \\ Patients}

There were no statistically significant differences in baseline clinical or imaging features between patients randomized to epidural corticosteroid and lidocaine versus lidocaine alone injection in the subset of patients included in this analysis $(n=350$, Table). Imaging studies were performed a median of 43 days from study enrollment with an interquartile range of 132 days (Q1 = 20 days and Q3 = 152 days). Seventy-four percent (260/350) of patients had at least 1 lumbar spine level of moderate or severe stenosis, and $50 \%(175 / 350)$ of patients had at least 1 lumbar spine level of severe stenosis.

\section{Epidural Injection Approach and Level}

The characteristics of epidural injections were similar between treatment groups.

Sixty-eight percent (239/350) of patients had interlaminar injections, and 32\% (111/350) had transforaminal injections. For 


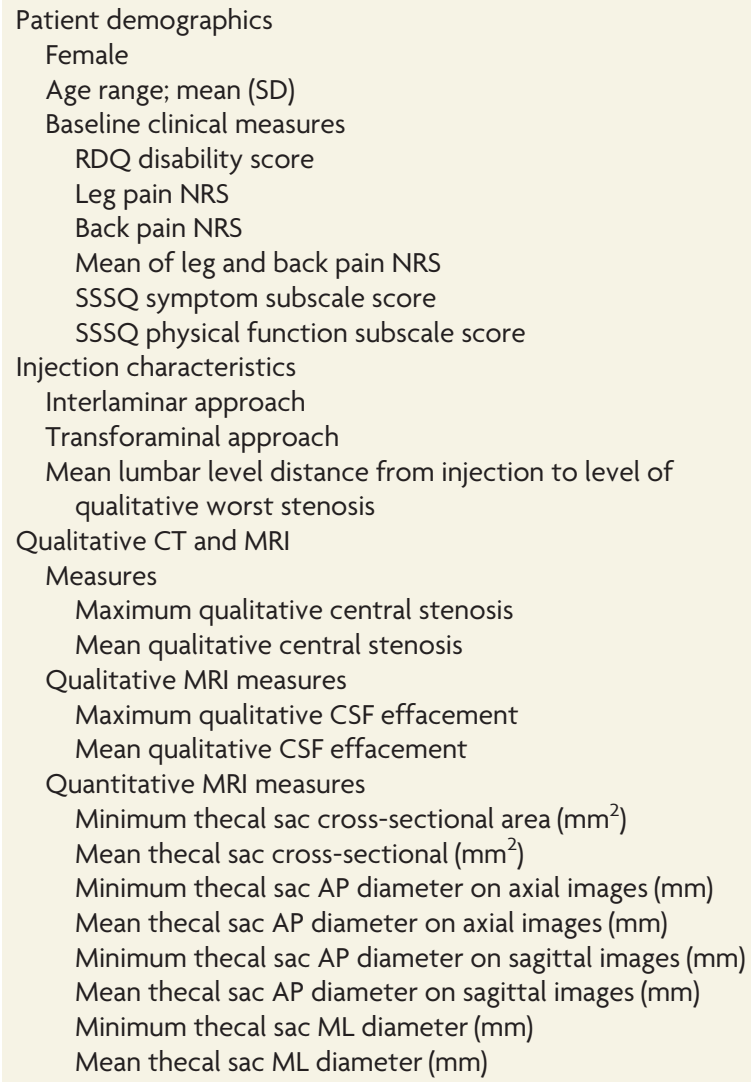

$53 \%(93 / 175)$
$50-96 ; 68(9.9)$

$15.6(4.3)$

$7.2(1.7)$

$6.6(2.6)$

$6.6(1.2)$

$3.1(0.6)$

$2.5(0.5)$

$68 \%(119 / 175)$

$32 \%(56 / 175)$

$0.6(0.6)$

$n=175$

$2.2(0.8)$

$1.2(0.4)$

$n=150$

$2.0(1.1)$

$0.7(0.6)$

$n=148$

$72(38)$

$130(40)$

$7.2(2.5)$

$10.6(2.0)$

$6.2(2.3)$

$9.5(2.0)$

$11.6(3.2)$

$16.1(2.7)$
$57 \%(100 / 175)$

50-89; 68 (9.6)

$16.1(4.5)$

$7.1(1.9)$

$6.6(2.4)$

$6.5(1.5)$

$3.2(0.6)$

$2.5(0.5)$

$69 \%(120 / 175)$

$31 \%(55 / 175)$

$0.5(0.7)$

$n=175$

$2.3(0.9)$

$1.2(0.5)$

$n=158$

$2.0(1.1)$

$0.7(0.6)$

$n=156$

73 (39)

$130(38)$

$7.2(2.4)$

$10.5(2.0)$

$6.4(2.4)$

$9.6(2.0)$

$11.6(3.1)$

$16.1(2.5)$

Note:-SSSQ indicates Swiss Spinal Stenosis Questionnaire.

${ }^{a}$ Values represent mean and SD unless otherwise specified.

each injection approach, half of patients received epidural corticosteroid and lidocaine and half received lidocaine alone (Table). Epidural injections were performed within 1 lumbar spinal level of the qualitatively worst stenosis in $92 \%$ of patients (321/350; for example, in a patient with a maximum stenosis at L5-S1, an interlaminar epidural injection at L4-L5 is 1 lumbar spinal level away and a transforaminal epidural injection at L5 is a one-half lumbar spinal level away). There was no difference in the mean distance of epidural injection from the level of maximum stenosis between treatment groups (Table, $P=.72$ ).

\section{Interrater Agreement for Evaluation of Imaging Studies}

For the primary qualitative imaging measure of the worst level of central stenosis (maximum qualitative central stenosis score), there was $74 \%$ agreement among the 2 experienced readers on a level-by-level basis (agreement in 261 of 355 lumbar spinal levels) with a $\kappa$ score of 0.72 , consistent with substantial agreement. ${ }^{25}$ On a per-patient basis, using the maximum spinal stenosis score for each patient indicating the worst level of stenosis, there was $86 \%$ agreement (61/71 patients) between the 2 experienced readers with a $\kappa$ score of 0.84 . For the primary quantitative imaging measure of the angle-corrected thecal sac cross-sectional area, there was excellent agreement among the 5 trained readers with an intraclass correlation coefficient of $0.91 .^{26}$

\section{Primary Imaging Measures as Predictors of Improvement in the RDQ Disability Score or Leg Pain NRS following Epidural Injection}

Regardless of the type of epidural injectate, study patients had an average 3.4-point improvement in the RDQ disability score (95\% $\mathrm{CI},-4.0$ to $-2.9 ; P<.0001)$ and an average 2.5 -point improvement in the leg pain NRS at 3 weeks $(95 \% \mathrm{CI},-2.8$ to $-2.2 ; P<$ $.0001)$. Patients who received corticosteroid with lidocaine injections had a slightly greater improvement in the RDQ disability score and leg pain NRS than patients injected with lidocaine alone at 3 weeks (adjusted mean differences for the RDQ, -1.7 points; $95 \% \mathrm{CI},-2.8$ to $-0.7 ; P<.01$; and for the leg pain NRS, -0.6 points; $95 \% \mathrm{CI},-1.2-0 ; P<.05)$ similar to rates previously reported. ${ }^{16}$ By means of the predetermined primary imaging measure of the maximum qualitative central stenosis score, patients with moderate central stenosis had slightly greater improvement in the RDQ disability score and leg pain NRS regardless of the type of injectate at 3 weeks (Fig 1) compared with those patients with mild stenosis (adjusted average treatment effect between moderate and mild central stenosis for RDQ, -2.1 points; $95 \% \mathrm{CI},-1.9$ to -0.6 ; $P<.05$; and for leg pain NRS, -1.0 point; $95 \% \mathrm{CI},-1.8$ to $-0.2 ; P<.05$ ) but not severe stenosis (adjusted average treatment effect between moderate and severe central stenosis for the RDQ, -1.3 points; $95 \% \mathrm{CI},-0.56-0.1 ; P=.15$; and for the leg pain NRS, -0.6 points; $95 \% \mathrm{CI},-1.4-0.1 ; P=.20$ ).

AJNR Am J Neuroradiol 40:908-15 May 2019 www.ajnr.org 

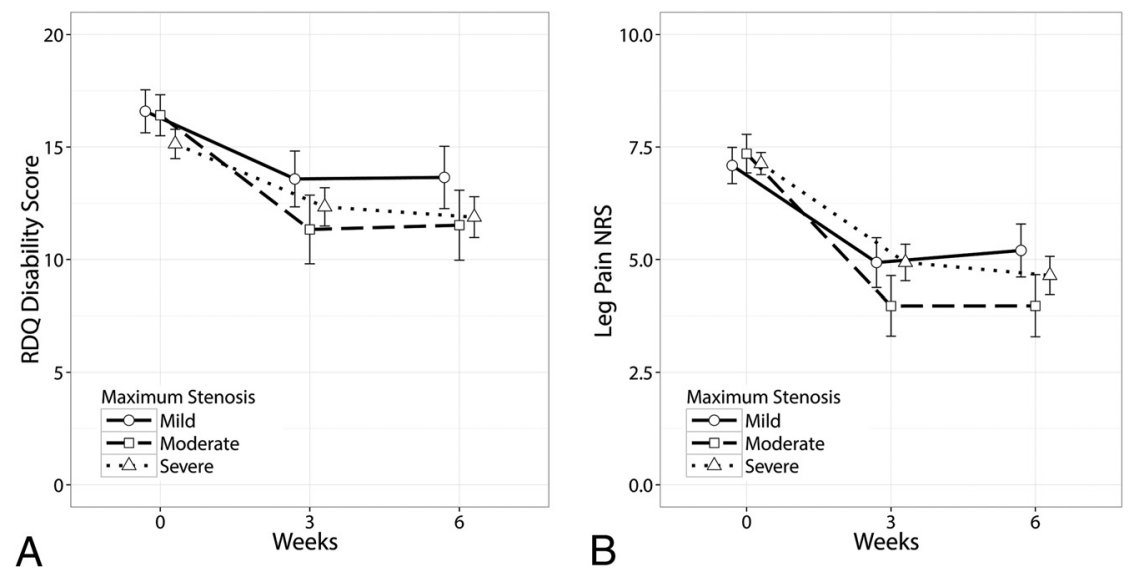

FIG 1. Mean and $95 \% \mathrm{Cl}$ for the RDQ disability score $(A)$ and the leg pain NRS $(B)$ are presented at baseline, 3 weeks, and 6 weeks following epidural injection, including all patients regardless of injectate type, and subdivided by the severity of spinal stenosis on imaging (mild $=$ solid line with circle; moderate = dash line with square; severe = dotted line with triangle). Patients with moderate stenosis demonstrated slightly greater improvement in disability scores at 3 weeks and leg pain scores at 3 and 6 weeks compared with patients with mild stenosis.
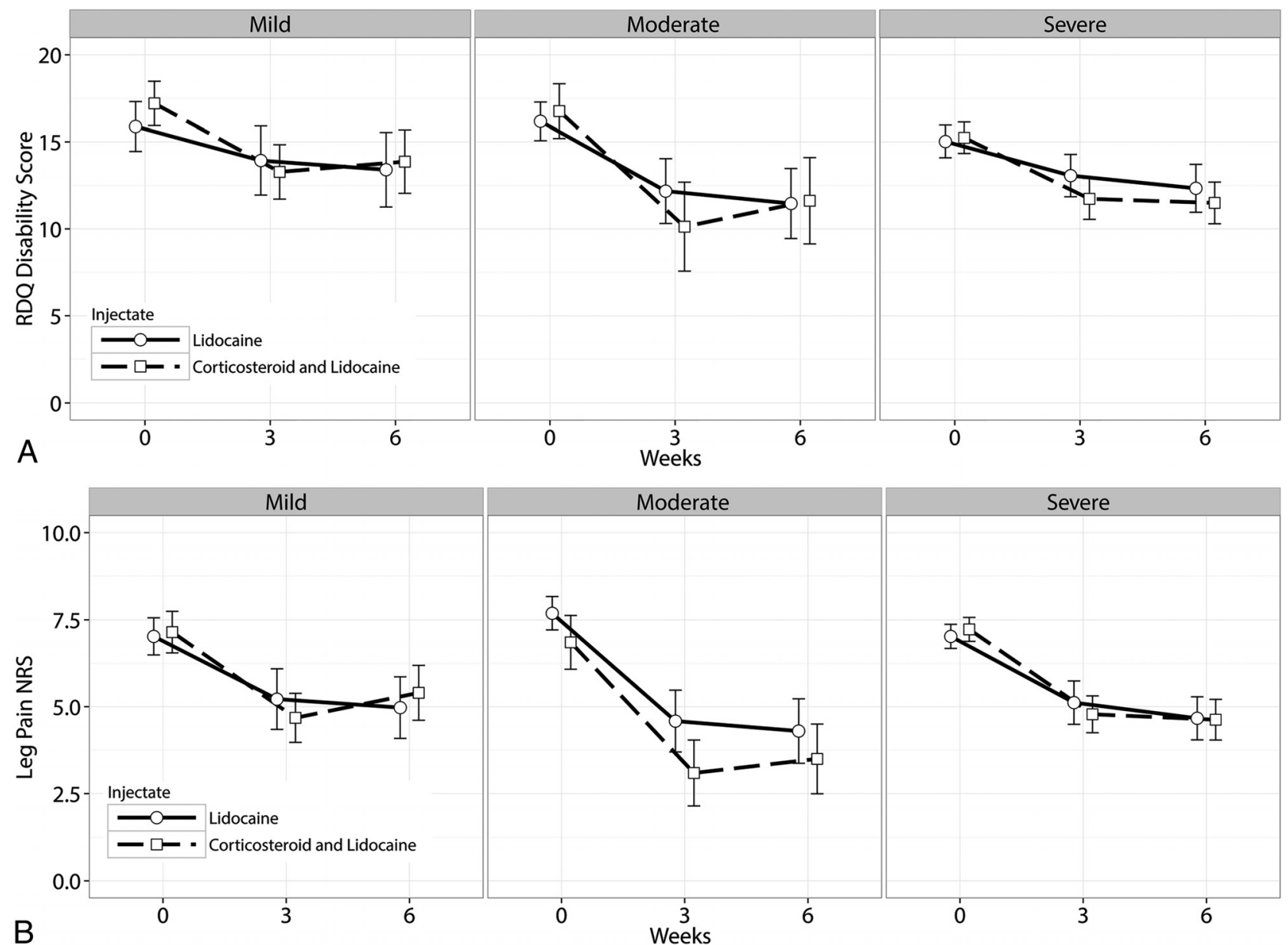

FIG 2. Mean and $95 \% \mathrm{CI}$ RDQ disability score $(A)$ and leg pain NRS $(B)$ at baseline, 3 weeks, and 6 weeks after epidural injection are presented for patients randomized to lidocaine alone (circles and solid line) and corticosteroid and lidocaine (squares and dotted line), subdivided by the severity of qualitative spinal stenosis on imaging (mild, moderate, and severe). There were no differences in responses when taking into account spinal stenosis severity.

Analysis of primary clinical outcomes using ANCOVA models that include interaction terms between primary imaging measures of spinal stenosis severity and epidural injectate revealed no difference in the degree of improvement in the RDQ disability scores or the leg pain NRS at 3 weeks using the imaging measures of the qualitative maximum central stenosis score (Fig 2; interaction coefficients of maximum central stenosis score and epidural injectate for RDQ, $-0.1 ; 95 \% \mathrm{CI},-1.3$ to $1.2 ; P=.90$; and for the leg pain NRS, $0.1 ; 95 \% \mathrm{CI},-0.6$ to $0.8 ; P=.81$ ) or the quantitative minimum thecal sac cross-sectional area (Fig 3; interaction 


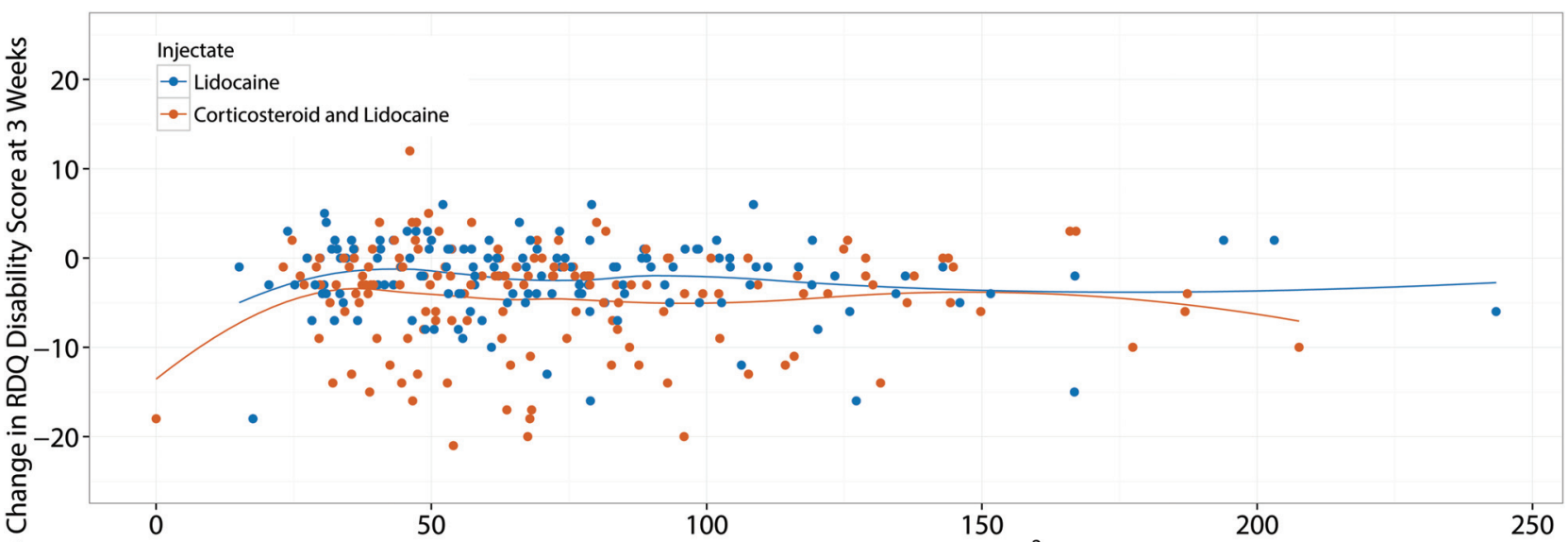

A

Min Thecal Sac Cross Sectional Area $\left(\mathrm{mm}^{2}\right)$

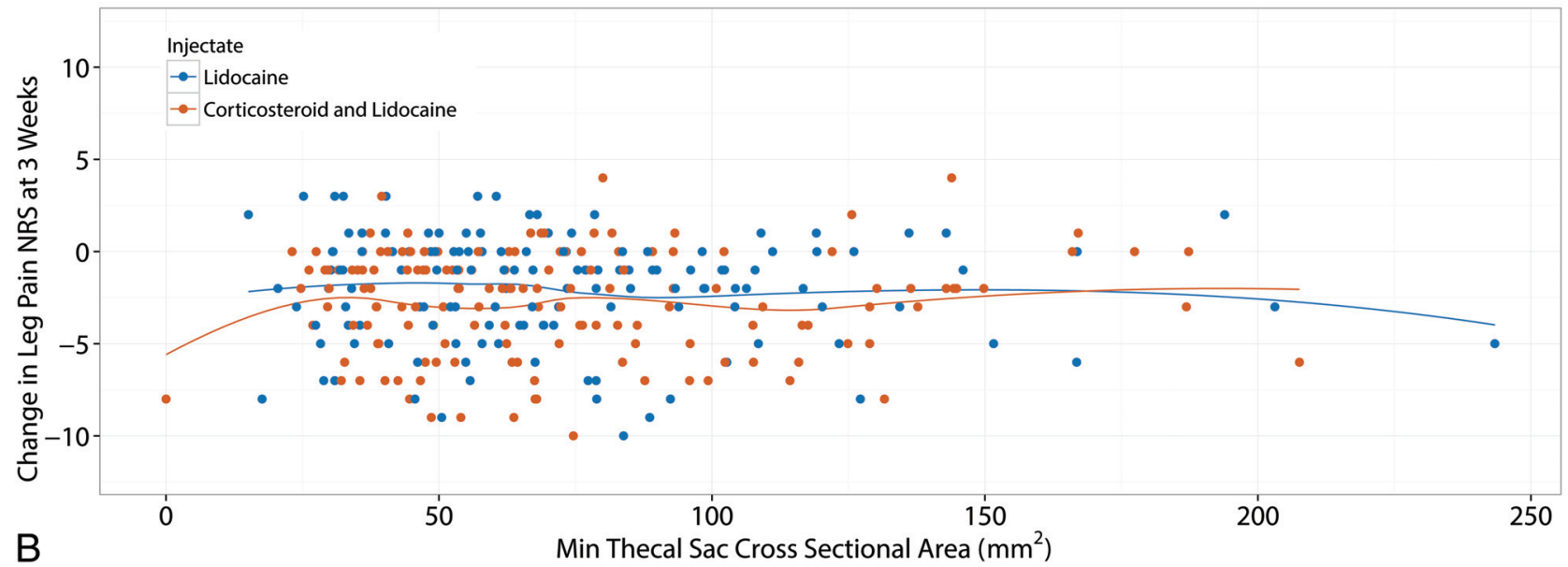

FIG 3. Change in the RDQ disability score $(A)$ and leg pain NRS $(B)$ at 3 weeks is presented as a function of minimum thecal sac cross-sectional area subdivided by injectate type with locally weighted scatterplot smoothing lines and $95 \% \mathrm{Cl}$ bands. The degree of spinal stenosis as assessed quantitatively was not associated with differential improvement between patients receiving lidocaine alone and corticosteroid and lidocaine. Min indicates minimum.

coefficients of minimum thecal sac cross-sectional area and epidural injectate for the RDQ, $0.01 ; 95 \% \mathrm{CI},-0.01$ to $0.03 ; P=.40$; and for the leg pain NRS, $0.01 ; 95 \% \mathrm{CI},-0.01$ to $0.03 ; P=.33$ ). Because the chronicity of pain could be a confounding variable, a self-reported duration of pain symptoms at enrollment was included as a covariate in ANCOVA models for the primary clinical end points and imaging measures at 3 weeks with similar results.

\section{Subgroup and Exploratory Data Analysis}

Subgroup analysis taking into account the injection approach (interlaminar versus transforaminal) and the distance of the injection from the maximum stenosis identified no significant interactions between the epidural injectate and primary imaging measures of spinal stenosis (On-line Tables 1 and 2). Exploratory statistical analyses using ANCOVA models with all combinations of clinical outcome measures (at 3 and 6 weeks) and imaging measures of spinal stenosis demonstrated no significant interactions to indicate a differential clinical response to injectate based on the severity of the spinal stenosis on imaging (On-line Tables 3 and 4). Additional subgroup analyses were performed by categorizing patients on the basis of the degree of improvement, at least $30 \%$ or $50 \%$, in the primary clinical outcome measures of the RDQ disability score or the leg pain NRS at 3 or 6 weeks. There were no differences in the primary imaging measures of maximum qualitative central stenosis or minimum thecal sac crosssectional area among these subgroups, regardless of responders versus nonresponders or injectate type (On-line Table 5).

\section{DISCUSSION}

In this secondary analysis of the CT and MR imaging studies of the LESS trial participants, we found no differences in baseline imaging characteristics between those receiving epidural corticosteroid and lidocaine and those receiving lidocaine alone injections. No imaging measures of spinal stenosis were associated with a differential response to corticosteroids, indicating that imaging parameters of spinal stenosis did not predict a response to epidural corticosteroids.

Prior studies evaluating the relationship between spinal stenosis imaging findings and the response to ESI are inconsistent, with most not demonstrating a clear association between the degree of stenosis and outcomes following ESI. Kapural et $\mathrm{al}^{27}$ found that patients with multilevel stenosis were more likely to improve following a series of ESIs than those with single-level stenosis, but degree of stenosis was not related to pain outcomes after a series of ESIs. The current study is in line with previously reported findings 
demonstrating a lack of association of spinal canal dimensions by CT with the outcome of the ESI ${ }^{11}$ and prior MR imaging-based studies demonstrating lack of a statistically significant difference between responders and nonresponders to ESI in the presence or absence of spinal stenosis ${ }^{12}$ or by stenosis severity. ${ }^{14,28}$

We hypothesized that patients with less severe central stenosis, for which inflammation may play a larger role than mechanical compression, would have a more favorable response to corticosteroid injections compared with treatment with lidocaine alone; however, we found that imaging measures of spinal stenosis were not associated with a differential degree of improvement. There was clinical improvement in both treatment groups, and overall slightly greater improvement was seen in patients with moderate stenosis compared with mild stenosis. Because there was improvement regardless of corticosteroid injection, the anti-inflammatory properties of corticosteroids may not have much of a role in the treatment of spinal stenosis. This clinical improvement could be due to the natural history of spinal stenosis, placebo effect, or lidocaine effect. A sham injection group was not included, and the efficacy of lidocaine alone could not be assessed. Our results do not exclude inflammation as a contributing factor in symptomatic spinal stenosis, though there are likely other factors that contribute to an individual patient's symptoms and possible differential response to therapy. Moreover, if inflammation is a contributing factor, spinal stenosis severity may not correlate with the degree of inflammation. Nevertheless, the severity of spinal stenosis on imaging was not a reliable biomarker to predict treatment response following epidural corticosteroid injection versus lidocaine alone, which adds to the many other patient characteristics, including demographics and chronicity of pain, that were previously also not found to reliably predict a differential response in the LESS trial. ${ }^{29}$

The current study has several limitations. First, the causes of spinal canal compromise (such as type of disc herniation, epidural lipomatosis, congenital stenosis, and facet or ligamentum flavum hypertrophy) and possible associated foraminal or lateral recess stenosis were not specifically assessed. Previous studies in other conditions, such as radiculopathy, have found that focal disc herniations and imaging severity of nerve root compression can predict short-term pain relief after ESI. ${ }^{10,13,30}$ Similarly, in a study that excluded patients with spinal stenosis, herniated discs in the foraminal and extraforaminal zones predicted a better response to ESI compared with discs in the central and subarticular zones. ${ }^{31}$ Moreover, Choi et $\mathrm{al}^{12}$ found no relationship between the response to ESI and spinal stenosis on MR imaging; however, they reported that the disc location and nerve root compression grades were associated with outcomes. Second, we did not localize a likely spinal level to account for each patient's symptoms in all cases, which would have enabled us to correlate potential imaging findings at a symptomatic level; nevertheless, epidural injections were performed within 1 lumbar spinal level of the worst stenosis in $>90 \%$ of patients, and transforaminal injections were targeted to the most symptomatic level. Third, the statistical power to detect interaction effects may be low, despite large sample sizes, due to multiple potential sources of heterogeneity, including pain and disability levels, treatment approaches, and type and dose of corticosteroids. However, small interaction effects are unlikely to have clinical utility to prospectively identify patients most likely to benefit from epidural corticosteroid injection compared with lidocaine alone for the treatment of symptomatic spinal stenosis.

\section{CONCLUSIONS}

The severity of lumbar spinal stenosis on CT or MR imaging in patients with a clinical diagnosis of lumbar spinal stenosis does not predict differential improvement in pain or disability following epidural corticosteroid with lidocaine injection compared with lidocaine injection alone.

\section{ACKNOWLEDGMENTS}

We thank the research staff for data collection and their overall dedication to this study. In addition, we would like to thank the LESS Scientific Advisory Board for their support.

Disclosures: Jeffrey G. Jarvik—RELATED: Grant: Agency for Healthcare Research and Quality, Comments: federal grant*; Support For Travel to Meetings for the Study or Other Purposes: Agency for Healthcare Research and Quality*; Fees for Participation in Review Activities Such as Data Monitoring Boards, Statistical Analysis, Endpoint Committees, and the Like: Agency for Healthcare Research and Quality*; Payment for Writing or Reviewing the Manuscript: Agency for Healthcare Research and Quality*; UNRELATED: Consultancy: UpToDate, Comments: section editor/consultant; Grants/Grants Pending: National Institutes of Health, Patient-Centered Outcomes Research Institute*; Payment for Lectures Including Service on Speakers Bureaus: Radiological Society of North America, Comments: Clinical Trials Methodology Workshop faculty member; Royalties: UpToDate, Springer Publishing; Travel/ Accommodations/Meeting Expenses Unrelated to Activities Listed: Association of University Radiologists (AUR) and General Electric (GE), Comments: GE-AUR Radiology Research Academic Fellowship annual retreat. Emin Aghayev-UNRELATED: Employment: Schulthess Clinic Zurich, Swiss Federal Government, University of Bern. Ella R. Jarvik—RELATED: Grant: Agency for Healthcare Research and Quality, Comments: 1R01HS01922201.* Andrew L. Avins—RELATED: Grant: Agency for Healthcare Research and Quality, Comments: as part of the Agency for Healthcare Research and Quality-funded multicenter clinical trial.* Jason M. Schwalb—RELATED: Grant: Agency for Healthcare Research and Quality, Comments: 1R01HS019222*; UNRELATED: Other: Blue Cross Blue Shield of Michigan, Comments: salary support for my role as Co-Director of the Michigan Spine Surgery Improvement Collaborative.* Christopher J. Standaert-RELATED: Grant: Agency for Healthcare Research and Quality, Patient-Centered Outcomes Research Institute.* David R. Nerenz-RELATED: Grant: Agency for Healthcare Research and Quality, Comments: standard research grant with funds used to cover the cost of conducting the study at our institution*; UNRELATED: Board Membership: Medicare Payment Advisory Commission, Comments: The Commission work involves the full range of Medicare payment issues. I served as a Medicare Payment Advisory Commission commissioner from 2012 to 2018; Employment: Henry Ford Health System, Comments: I was a full-time employee of the Henry Ford Health System during the entire time covered by this disclosure. Thiru Annaswamy-RELATED: Grant: Agency for Healthcare Research and Quality, Comments: The LESS study was funded by the Agency for Healthcare Research and Quality*; UNRELATED: Employment: federal government, Comments: I am a full-time employed physician at the VA. Zoya Bauer-RELATED: Grant: Agency for Healthcare Research and Quality.* Srdjan S. Nedeljkovic-RELATED: Grant: Brigham and Women's Hospital.* Janna L. Friedly_RELATED: Grant: Agency for Healthcare Research and Quality, Patient-Centered Outcomes Research Institute.* PatrickJ. Heagerty—RELATED: Grant: National Institutes of Health.* *Money paid to the institution.

\section{REFERENCES}

1. Deyo RA, Gray DT, Kreuter W, et al. United States trends in lumbar fusion surgery for degenerative conditions. Spine 2005;30:1441-45; discussion 1446-47 CrossRef Medline

2. Taylor VM, Deyo RA, Cherkin DC, et al. Low back pain hospitalization: recent United States trends and regional variations. Spine 1994;19:1207-12; discussion 13 CrossRef Medline

3. Steurer J, Roner S, Gnannt R, et al. Quantitative radiologic criteria for the diagnosis of lumbar spinal stenosis: a systematic literature review. BMC Musculoskelet Disord 2011;12:175 CrossRef Medline

4. Kovacs FM, Urrútia G, Alarcón JD. Surgery versus conservative treatment for symptomatic lumbar spinal stenosis: a systematic re- 
view of randomized controlled trials. Spine 2011;36:E1335-51 CrossRef Medline

5. Moojen WA, Schenck CD, Lycklama À Nijeholt GJ, et al; Leiden-The Hague Spine Intervention Prognostic Study Group (SIPS). Preoperative MRI in patients with intermittent neurogenic claudication: relevance for diagnosis and prognosis. Spine 2018;43:348-55 CrossRef Medline

6. Harrast MA. Epidural steroid injections for lumbar spinal stenosis. Curr Rev Musculoskelet Med 2008;1:32-38 CrossRef Medline

7. Friedly J, Chan L, Deyo R. Increases in lumbosacral injections in the Medicare population: 1994 to 2001. Spine 2007;32:1754-60 CrossRef Medline

8. Friedly J, Nishio I, Bishop MJ, et al. The relationship between repeated epidural steroid injections and subsequent opioid use and lumbar surgery. Arch Phys Med Rehabil 2008;89:1011-15 CrossRef Medline

9. Abdi S, Datta S, Trescot AM, et al. Epidural steroids in the management of chronic spinal pain: a systematic review. Pain Physician 2007;10:185-212 Medline

10. Ghahreman A, Bogduk N. Predictors of a favorable response to transforaminal injection of steroids in patients with lumbar radicular pain due to disc herniation. Pain Med 2011;12:871-79 CrossRef Medline

11. Campbell MJ, Carreon LY, Glassman SD, et al. Correlation of spinal canal dimensions to efficacy of epidural steroid injection in spinal stenosis. J Spinal Disord Tech 2007;20:168-71 CrossRef Medline

12. Choi SJ, Song JS, Kim C, et al. The use of magnetic resonance imaging to predict the clinical outcome of non-surgical treatment for lumbar intervertebral disc herniation. Korean J Radiol 2007;8: 156-63 CrossRef Medline

13. Paidin M, Hansen $P, M c F a d d e n ~ M$, et al. Contrast dispersal patterns as a predictor of clinical outcome with transforaminal epidural steroid injection for lumbar radiculopathy. $P M R$ 2011;3:1022-27 CrossRef Medline

14. Park $\mathrm{CH}$, Lee SH. Correlation between severity of lumbar spinal stenosis and lumbar epidural steroid injection. Pain Med 2014;15: 556-61 CrossRef Medline

15. Benny BV, Patel MY. Predicting epidural steroid injections with laboratory markers and imaging techniques. Spine J 2014;14: 2500-08 CrossRef Medline

16. Friedly JL, Comstock BA, Turner JA, et al. A randomized trial of epidural glucocorticoid injections for spinal stenosis. $N$ Engl J Med 2014;371:11-21 CrossRef Medline

17. Andersson GB. Epidural glucocorticoid injections in patients with lumbar spinal stenosis. N Engl J Med 2014;371:75-76 CrossRef Medline

18. Friedly JL, Bresnahan BW, Comstock B, et al. Study protocol: Lumbar Epidural steroid injections for Spinal Stenosis (LESS) - a dou- ble-blind randomized controlled trial of epidural steroid injections for lumbar spinal stenosis among older adults. BMC Musculoskelet Disord 2012;13:48 CrossRef Medline

19. Paisley K, Jeffries J, Monroe M, et al. Dispersal pattern of injectate after lumbar interlaminar epidural spinal injection evaluated with computerized tomography. Global Spine J 2012;2:27-32 CrossRef Medline

20. Lee JH, An JH, Lee SH. Comparison of the effectiveness of interlaminar and bilateral transforaminal epidural steroid injections in treatment of patients with lumbosacral disc herniation and spinal stenosis. Clin J Pain 2009;25:206-10 CrossRef Medline

21. Stucki G, Daltroy L, Liang MH, et al. Measurement properties of a self-administered outcome measure in lumbar spinal stenosis. Spine 1996;21:796-803 CrossRef Medline

22. Lurie JD, Tosteson AN, Tosteson TD, et al. Reliability of readings of magnetic resonance imaging features of lumbar spinal stenosis. Spine 2008;33:1605-10 CrossRef Medline

23. Andreisek G, Deyo RA, Jarvik JG, et al; LSOS working group. Consensus conference on core radiological parameters to describe lumbar stenosis: an initiative for structured reporting. Eur Radiol 2014; 24:3224-32 CrossRef Medline

24. Lee GY, Guen YL, Lee JW, et al. A new grading system of lumbar central canal stenosis on MRI: an easy and reliable method. Skeletal Radiol 2011;40:1033-39 CrossRef Medline

25. Landis JR, Koch GG. The measurement of observer agreement for categorical data. Biometrics 1977;33:159-74 CrossRef Medline

26. Fleiss JL. The Design and Analysis of Clinical Experiments. Hoboken John Wiley \& Sons, Inc; 1986:1-32

27. Kapural L, Mekhail N, Bena J, et al. Value of the magnetic resonance imaging in patients with painful lumbar spinal stenosis (LSS) undergoing lumbar epidural steroid injections. Clin J Pain 2007;23: 571-75 CrossRef Medline

28. Cosgrove JL, Bertolet M, Chase SL, et al. Epidural steroid injections in the treatment of lumbar spinal stenosis efficacy and predictability of successful response. Am J Phys Med Rehabil 2011;90:1050-55 CrossRef Medline

29. Turner JA, Comstock BA, Standaert CJ, et al. Can patient characteristics predict benefit from epidural corticosteroid injections for lumbar spinal stenosis symptoms? Spine J 2015;15:2319-31 CrossRef Medline

30. Maus TP, El-Yahchouchi CA, Geske JR, et al. Imaging determinants of clinical effectiveness of lumbar transforaminal epidural steroid injections. Pain Med 2016;17:2176-84 CrossRef Medline

31. Lee JW, Choi SW, Park SH, et al. MR-based outcome predictors of lumbar transforaminal epidural steroid injection for lumbar radiculopathy caused by herniated intervertebral disc. Eur Radiol 2013; 23:205-11 CrossRef Medline 